\title{
Effects of DanceSport on walking balance and standing balance among the elderly
}

\author{
Jeehoon Sohn ${ }^{\mathrm{a}}$, Sung-Ha Park ${ }^{\mathrm{b}}$ and Sukwon Kim ${ }^{\mathrm{c}, *}$ \\ ${ }^{a}$ Department of Physical Education, College of Cultural Industry, Arts, and Sports, Jeonju University, \\ Jeonju, Korea \\ ${ }^{\mathrm{b}}$ Industrial and Systems Engineering, Hannam University, Daejeon, Korea \\ ${ }^{\mathrm{c}}$ Department of Physical Education, College of Education, Research Institute of Physical Education, \\ Chonbuk National University, Jeonju, Korea
}

\begin{abstract}
.
BACKGROUND: Dancesport is a popular activity among older adults who look for fun and fitness in Korea. Studies reported positive sociological and psychological effects of dancesport. But, little studies were performed to evaluate the effects of dancesport on balance performances.

OBJECTIVE: The objective of the present study was to evaluate the effects of dancesport for 15 weeks on walking balance and standing balance of older adults.

METHODS: Older adults regularly participated in the dancesport program 3 times a week for 15 weeks. The program included Rumba, Cha-cha-cha, and Jive. They exercised the prescribed dancesport at intermediate level for 50-60 mins for each time. A total 22 reflective markers were placed on the anatomical landmarks and 8 cameras were used to measure 3-D positions of participants. Also, center of pressure (COP) data were measured to analyze standing balance using a ground reaction board at $1200 \mathrm{~Hz}$ for 30 seconds. One-way analysis of variance (ANOVA) was performed to test the effects of 15 weeks of dancesport on walking balance and standing balance.

RESULTS: The results suggested that, after 15 weeks of dancesport participation, older adults' walking balance (48.3 \pm $20.3 \mathrm{~cm}^{2}$ vs $38.2 \pm 18.2 \mathrm{~cm}^{2}$ ) and standing balance (COP area: $189.4 \pm 85.4 \mathrm{~mm}^{2}$ vs $103.5 \pm 55.4 \mathrm{~mm}^{2}$, COP distance: 84.2 $\pm 34.4 \mathrm{~cm}$ vs $76.5 \pm 21.4 \mathrm{~cm}$ ) were significantly improved.

CONCLUSION: Performing dancesport would require moving center of mass rapidly and frequently while maintaining posture. This may result in improving walking balance and standing balance in the present study. The study concluded that dancesport would be an effective exercise method in enhancing postural stability of older adults.
\end{abstract}

Keywords: Dancesport, stability, balance, walking, falls, elderly

\section{Introduction}

Falls tended to increase with advancing age [1-4]. Rapid developments in medical and science domains are accompanied with a growth in older population who is at the higher risk of falling. Falls was the leading cause of premature death, physical injury, bone fracture, head injuries, psychosocial dysfunction, and admittance to long-term care facilities. 50-60\% of them could not restore their health to

\footnotetext{
${ }^{*}$ Corresponding author: Sukwon Kim, Department of Physical Education, College of Education, Research Institute of Physical Education, Chonbuk National University, Jeonju, Korea. Tel.: +82 63270 2860; Fax: +82 63270 2850; E-mail: rockwall@jbnu.ac.kr.
}

0928-7329/18/\$35.00 (c) 2018 - IOS Press and the authors. All rights reserved

This article is published online with Open Access and distributed under the terms of the Creative Commons Attribution NonCommercial License (CC BY-NC 4.0). 
previous levels leading to early death [2,5-7]. Postural instability or abnormal walking characteristics was suggested to influence fallings of older adults [2,5,6,8-10].

Postural control is the ability to control the position of the body's center of mass (COM) over its base of support (BOS) to prevent the body from falling $[11,12]$. Postural stability is maintained when the COM falls within the BOS [12]. During standing, it is maintained by a continuous effort of the neuromuscular systems by integrating sensory information and executing appropriate postural responses [13-15]. Postural stability, commonly assessed by the center of pressure (COP), has been a critical factor for identifying risk of falling [12,16-18]. An evaluation of postural sway by a measure of COP displacement is a common method for assessing postural stability during standing and has been widely used for evaluating neurologic or biomechanical mechanism of postural control $[13,14,16,17]$. Postural sway during standing tended to increase because of physiological deterioration of neuromuscular components with aging [19-21].

Without proper lower extremity strength, a person's body would not travel safely and efficiently while walking since the lower limb support or transition would occupy a large percentage of typical walking. In order for the elderly to transport the whole body forward safely and stably, appropriate ankle joint torque should be produced. With advancing age, the whole body transfer without intact neuromuscular responses at the ankle joint would be very challenging. Decreases in range of motion or muscle strength at ankle joint in older adults may result in the unstable gait patterns or balance contributing to fallings among older adults.

The cyclic nature of human gait, which, is essential for normal walking, come of sequential activations or deactivations of seven lower extremity muscles (hamstring, quadriceps, gluteus maximux and midius, tibialis anterior, adductor magnus, and gastrocnemius) [10,22]. These muscles during normal walking would accelerate or decelerate angular motions of lower extremities [10,23]. Untimely responses of these muscles due to the aging neuromuscular components can incur troubles in governing the periodic leg movement. As a result, the elderly is opt to demonstrate loss of dynamic stability leading to fallings [810].

Deteriorations in neuromuscular components with advancing age are commonly accompanied with mobility problems and a decreased physical capability leading to insecure and unconfident balance and gait $[5,9,10,24-26]$. Poor gait stability or unstable postural control had harmful effects on older adults leading to falls $[8,10,24,27]$. It is well known that exercises have positive effects in elderly falls, especially, exercises targeting balance and gait stability. These exercises were found to be effective on improving muscle strength, sensorimotor function in legs which were related to physical capability, mobility, and postural control $[8,10,25,27-30]$.

Dancesport is currently one of the most popular physical activities among older adult in South Korea and the world since dance-based exercise intervention makes the exercise more interesting to older adults $[26,31,32]$. It was found that various types of dance participation could improve older adults' leg strength, endurance, balance, and flexibility $[33,34]$. Given the results from the previous studies $[26,33,34]$, dance sport can be thought to play a role in improving postural stability, which, is an essential component in preventing falls among older adults. Operations in dancesport, such as, forwardwalk, backward-walk, and sideward-walk could influence balance and gait stability, and sway and turn could influence mechanisms which control maintaining center of mass within a base of support [35]. However, effects of dancesport on falls among older adults have not been identified effectively.

The ultimate purpose of the study was to identify the effect of dancesport on gait and postural stability of older people. In particular, the study aimed to analyze the details of the changes in neuromuscular responses using center of mass and center of pressure. 
Table 1

Mean and standard deviation of age, weight, and height

\begin{tabular}{ccc}
\hline Age $(n=15)$ & Weight $(\mathrm{kg})$ & Height $(\mathrm{cm})$ \\
\hline $72 \pm 5.4$ & $59.7 \pm 8.4$ & $158.6 \pm 7.7$ \\
\hline
\end{tabular}

\section{Method}

\subsection{Subject}

Fifteen older participants (Table 1) from a local Senior Welfare Center participated in this program for 15 weeks. They all signed informed consent form approved by university IRB. The Physical Activity Readiness Questionnaire (PAR-Q) was used to initially screen out physically inactive persons. Then, participants were excluded from the study if they indicated any physical problems (i.e. ankle, knee, or hip problems). During 15 weeks of the exercise program, their daily activities were monitored and no participants engaged to any other sports or physical activities.

\subsection{Treatment}

Dancesport program included Rumba, Jive, and Cha-cha-cha, which were Latin dances (Table 2). Participants were instructed to perform the dance for 50 minutes per session which was held three times a week. The program lasted for 15 weeks. For each session, participant began from beginner level to intermediate level. Target heart rate was set for $50 \sim 60 \%$ of HRmax, about $75 \sim 90 \mathrm{bpm}$ throughout the period, not exceeding 70\% of HRmax (about $105 \mathrm{bpm}$ ).

\subsection{Apparatus}

A total of 22 reflective markers were placed over the bony landmarks of the participants (anterior portion of temporal bone (2), greater tubercle (2), acromion (2), lateral epicondyle of humerus (2)), styloid process of ulna (2), base of first phalange of third finger (2), anterior superior iliac crest (2), epicondyle (4), lateral malleolus (2), base of second toe (2 markers). 3-D positions of participant's walking were collected using an eight-camera OptiTrack S250e system (Natural Point, Inc, Oregon, USA). Participants were asked to walk along a defined area $(15 \mathrm{~m} \times 2 \mathrm{~m})$. They started walking from one end to the other end (15 m long), and at the other end, stopped and turned around walking back toward the starting end ( $15 \mathrm{~m}$ long). They walked a total of 20 cycles. Kinematic data were sampled and recorded at $120 \mathrm{~Hz}$.

Postural reactions were measured using a force platform (AMTI OR6-7-1000, AMTI, MA, USA) with sampling rate of $1200 \mathrm{~Hz}$ for 30 seconds. When they seemed to stand still, the data collection began. With these data, the length of postural sway path in anterior-posterior (AP) and medio-lateral (ML) direction and the position variability of center of pressure (COP) and were computed [37].

\subsection{Dependent variables}

The whole body Center of mass (bCOM) was computed by averaging the centers of mass of the 14 segments ( 2 feet, 2 shanks, 2 thighs, trunk, 2 hands, 2 lower arms, 2 upper arms, head) [24]. COM 
Table 2

Description of Dancesport program for the present study (adapted from [36])

\begin{tabular}{|c|c|c|c|c|c|}
\hline & & Exercise program contents & Period & Intensity & Freq \\
\hline Warm up & Stretching & & $5 \mathrm{~min}$ & & 3 times \\
\hline \multirow{18}{*}{$\begin{array}{l}\text { Main } \\
\text { exercise }\end{array}$} & \multirow[t]{5}{*}{ Rumba } & Cuban Rocks, Alternative Basic & \multirow{18}{*}{$45 \mathrm{~min}$} & \multirow{18}{*}{$\begin{array}{l}\text { - Moderate exercise intensity: } \\
\text { 1. } 50 \sim 60 \% \text { HR Max. } \\
\text { 2. Breathing quickens, but not out } \\
\text { of breath. } \\
\text { 3. A light sweat after } 10 \text { mins. } \\
\text { 4. Conversation, but no singing. }\end{array}$} & a week \\
\hline & & Movement, Open Basic, Right U/A Turn, & & & \\
\hline & & Check from Open C.P.P and P.P, Spot & & & \\
\hline & & Turn to Left, Side step to Left, & & & \\
\hline & & Chcharachas & & & \\
\hline & Cha-Cha-Cha & Right Under Turn, New York, Spot Turn & & & \\
\hline & & to Left, Time Step, Shoulder to Shoulder, & & & \\
\hline & & Side Step to Right, There and Back, & & & \\
\hline & & Three ChaChaCha to Forward/Backward, & & & \\
\hline & & Hand to Hand, Close Basic to Fan & & & \\
\hline & Jive & Basic in Place, Basic in Fallaway, & & & \\
\hline & & Change of place Right to Left, Link, & & & \\
\hline & & Fallaway Throwaway, Change of Hand & & & \\
\hline & & behind Back, Hip Bump, Whip, Jive & & & \\
\hline & & Walks, Stop and Go, American Spin, & & & \\
\hline & & Link and Mooch, Throwaway and Whip & & & \\
\hline & & Throwaway, Double Whip Cross, Curly & & & \\
\hline & & Whip & & & \\
\hline Cool down & Stretching & & $5 \min$ & & \\
\hline
\end{tabular}

position of the entire mass is sum of the individual segment mass and com products divided by the total mass Eq. (1).

$$
x_{c m}=\frac{\sum_{i=1}^{n} m_{i} x_{i}}{M} \quad y_{c m}=\frac{\sum_{i=1}^{n} m_{i} y_{i}}{M} \quad z_{c m}=\frac{\sum_{i=1}^{n} m_{i} z_{i}}{M}
$$

where $\mathrm{cm}$ is the center of mass, $m_{i}$ is the mass of segment, $x_{i}, y_{i}, z_{i}$ are the distance from segment end, $M$ is the total mass (weight of a person).

Step length (SL) was defined as the linear distance in horizontal (X) direction from heel contact of left foot to heel contact of right foot.

Walking balance $\left(\mathrm{WB}, \mathrm{cm}^{2}\right)$ was assessed using factor analysis (multivariate analysis) which was a statistical method to detect a structure or a pattern. bCOM in medial-lateral direction (COM y) and bCOM in vertical direction (COM z) were recognized as two different factors (Fig. 2). The eigenvalue for each factor measured the variance in all the variables. Since the two factors (COM y and COM z) accounted for 100 percent of the variance of the two sets of data, the two eigenvalues were used to create ellipsoidal area [8]. Greater an ellipsoidal area commonly suggested bigger variability of COM in medio-lateral and/or vertical directions. The bigger variability suggested larger sway of the body during walking. Greater sway during leg support or transition may lead to falls.

Standing balance $(S B)$ was assessed while standing quietly. Using factor analysis already described above, the eigenvalues for center of pressure (COP) in $\mathrm{x}$ and y directions were computed and measured the variance on each factor. Ellipsoidal areas $\left(\mathrm{CA}, \mathrm{mm}^{2}\right)$ were computed by one eigenvalue as a long axis and the other eigenvalue as a short axis [37]. Greater static balance control was suggested if the computed ellipsoidal area was smaller; smaller ellipsoidal area indicated lesser variance. In addition, COP distance $(C D, \mathrm{~cm})$ was computed to assess the reaction mechanisms; COPdistance $=X(i+1)-X(i)$, where $X=$ position of COP. Average of the COP distance during 30 second standing was parameterized. 


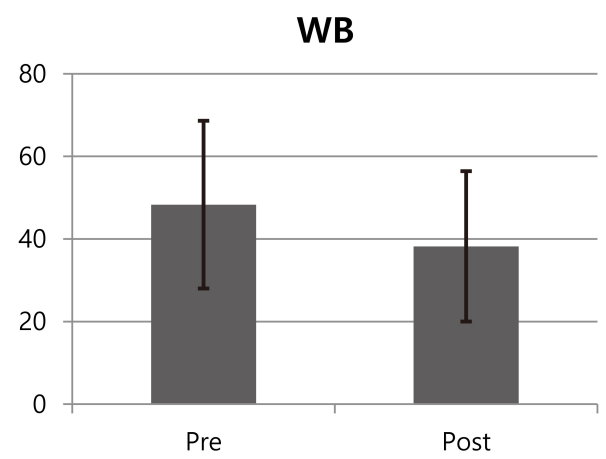

Fig. 1. Mean and SD of WB (unit: $\mathrm{cm}^{2}$ ).

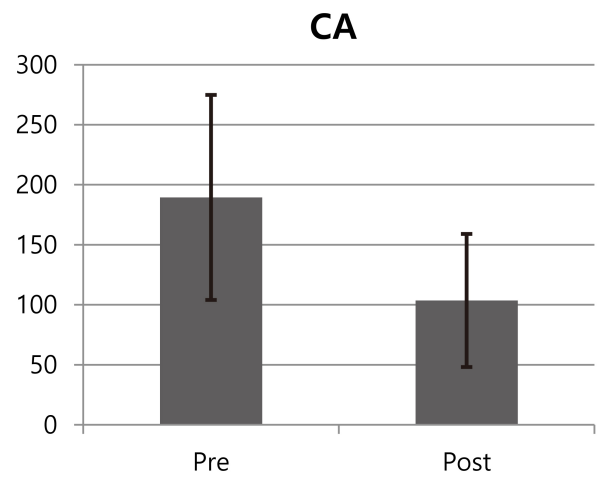

Fig. 2. Mean and SD of CA (unit: $\mathrm{mm}^{2}$ ).

\subsection{Statistical method}

Walking balance (WB) and standing balance (CA and $\mathrm{CD}$ ) were evaluated at pre- and post-training. One-way ANOVA was performed by utilizing SPSS 12. The results were considered as statistically significant when $p \leqslant 0.05$.

\section{Results}

\subsection{Walking balance (WB)}

WB was statistically different (Fig. 1) between post-training $\left(38.2 \pm 18.2 \mathrm{~cm}^{2}\right)$ and pre-training $(48.3$ $\left.\pm 20.3 \mathrm{~cm}^{2}\right)$ after participating in 15 weeks of dancesport program $(p=0.04)$.

\subsection{Standing balance $(S B)$}

CA was statistically different (Fig. 2) between post-training $\left(103.5 \pm 55.4 \mathrm{~mm}^{2}\right)$ and pre-training $\left(189.4 \pm 85.4 \mathrm{~mm}^{2}\right)$ after participating in 15 weeks of dancesport program $(p=0.004)$. CD was statistically different $($ Fig. 3$)$ between post-training $(76.5 \pm 21.4 \mathrm{~cm})$ and pre-training $(84.2 \pm 34.4 \mathrm{~cm})(p=$ 0.03). Better stability was considered if CA was smaller and CD was shorter (Fig. 4). 


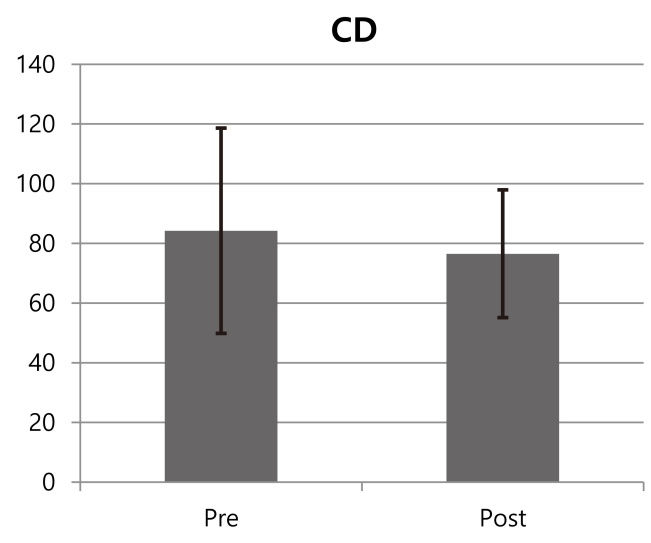

Fig. 3. Mean and SD of CD (unit: $\mathrm{cm}$ ).
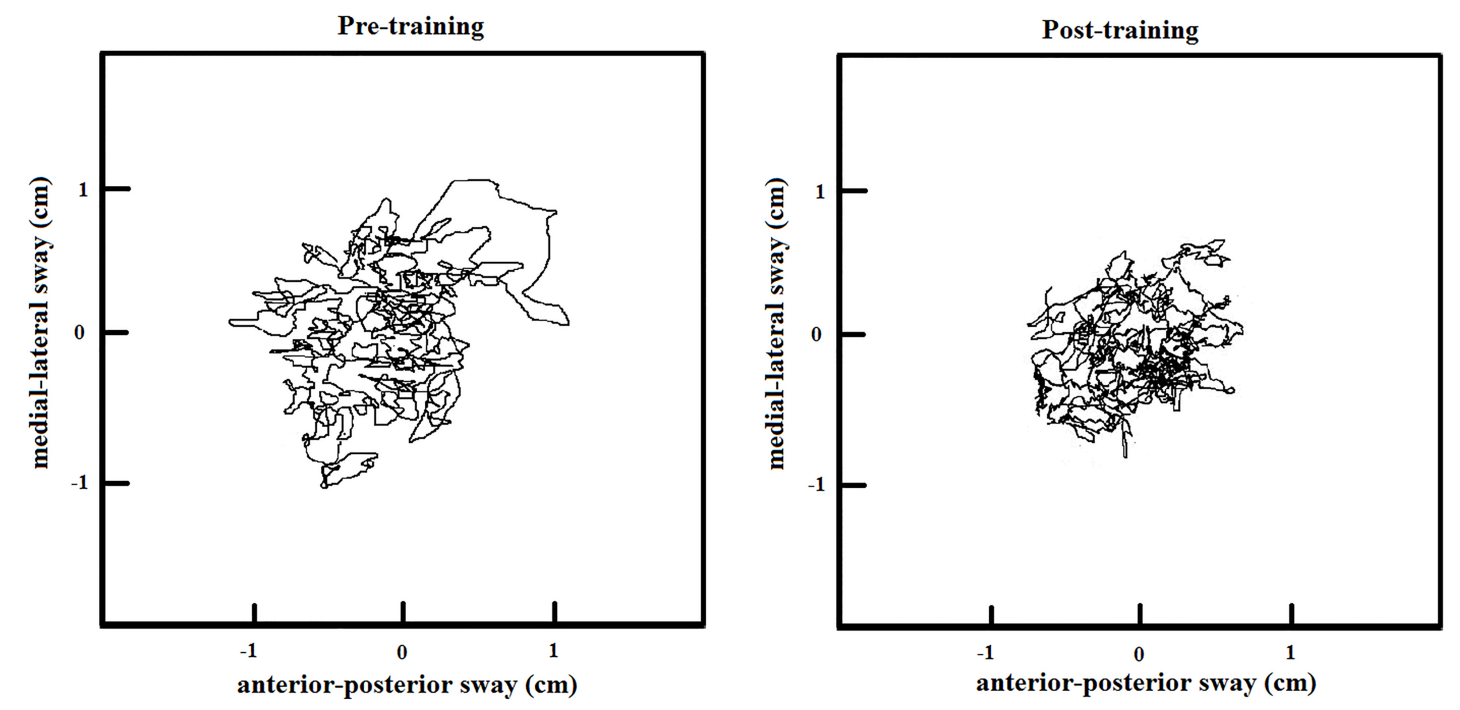

Fig. 4. COP plots of before and after 15 week training.

\section{Discussion}

The objective of the present study was to evaluate if performing dancesport could improve walking balance and standing balance of older adults. In agreement of the previous studies [34,38,39], the present study also found that postural stability of older aduults was improved after 15 weeks of dancesport participation.

With advancing age, people tend to lose their ability in maintaining postural stability while standing $[24,25,40]$ or walking $[9,10,25]$. The net neuromuscular response of the central nervous system (CNS) controls human standing or walking [41] and, generally, the enhancements of neural recruitment patterns is likely to improve postural stability $[42,43]$. In the present study, it was expected that, after performing 15 weeks of sport dances, a variety of motor abilities or skills of older adults would improve $[33,44-46]$. Additionally, their ability to contract or relax lower limb muscles in timely manner was expected to improve while standing or walking since it was positively associated with the necessary 
dynamics of the dance performance [44]. Likewise, to attain successful postural balance during walking or quiet standing, it is important to maintain intact lower body reactions or movements; lower extremity plays a dominant active role in corrective response [8,47]. The improvements in neural recruitment responses enhanced stability or balance control during standing or walking [10,43]. In the present study, standing balance as well as walking balance improved after 15 weeks of dancesport training. The results could suggest that dancesport training for older adults could improve their ability of neuromuscular response to control lower extremity muscles resulting in enhancements of postural stability (WB and $\mathrm{SB})$.

The abdominal muscle group and the back extensors were associated with maintaining the upright posture while walking during standing [48,49]. Also, the plantarflexors and dorsiflexors of the ankle, knee flexors and extensors, and hip extensors were also found to be important muscles in postural control of lower extremity [50,51]. Dancesport needs the quick-tempered activations of lower extremity muscles in order to change the position rapidly and progressively while maintaining the correct positioning of the upper part of the body [44]. To maintain the correct position of the upper body while performing Rumba, Chachacha, or Jive requires sufficient strength in abdominal and back extensor muscles. Although the strength improvements in these muscles were not evaluated in the present study, maintaining upright posture of upper body while performing the repetitive and explosive dancesport movements must have stimulated and strengthened abdominal and back extensor muscles [44] leading to improvements in postural stability (WB or SB) for older adults in the present study.

Dancesport is composed of many functional movements such as walking, running, jumping, forward movement, backward movement, spinning, tip-toeing, heel rising, and turning resulting in equal developments of lower extremity muscle strength and flexibility of lower extremity joints [34]. Levels of knee muscle strength were found to relate to degrees of dynamic postural stability $[18,34,52]$. Kim et al. [39] suggested that dancesport, which exhibited wide variety of movements in all directions, could influence an ability to equally control knee muscles leading to the improvement in postural stability. Wu et al. [34] found that low-impact dance, composed of side-stepping, forward and backward walking, circling, lifting legs, tiptoeing with the foot and heel rising, could positively influence knee muscle strength, flexibility of lower extremity joints, and dynamic balance of older female adults. Kim et al. [39] found that, after 8 weeks of dancesport training, participants (55 years or older women) showed improvements in knee flexor and extensor muscles as well as one-leg standing. The study suggested that knee flexor and extensor muscle strength would be positively related to the performance levels of one-leg standing. The enhancements in postural stability of older adults in the present study may be explained by knee strength and flexibility improvements found in the previous studies [18,34,52].

As informed in the previous study [34] participating low-impact dance could improve ankle flexibility. Lower extremity flexibility was suggested to influence postural stability or body balance [52-54]. Williams et al. [52] found that ankle dorsiflexion range of motion was directly associated with dynamic postural stability. Iwamoto et al. [53] suggested that hip joint flexibility (hip abduction and adduction) was positively associated with balance ability in older adults. Winter [11] suggested that the ankle flexibility and strength was a dominant factor in balance control when there was no or a small external perturbations since ankle plantarflexors and dorsiflexors alone would act to control the inverted pendulum. Still, during a larger perturbation, the ankle muscles alone could not act to control the inverted pendulum as muscles at hip joint responded to flex the hip to move the center of mass in front of body. It was speculated from the previous studies [11,34,52-54] that 15 weeks of dancesport training improved ankle and hip joint flexibility leading to improvements in postural balance (WB and SB) in the present study. 


\section{Conclusion}

The present study suggested that dancesport could be an effective exercise method in order for older adults to improve postural stability such as walking or standing.

\section{Acknowledgments}

This work was supported by the National Research Foundation of Korea Grant funded by the Korean Government (NRF- 2013R1A1A1013797).

\section{Conflict of interest}

None to report.

\section{References}

[1] Nicklett EJ, Taylor RJ. Racial/Ethnic predictors of falls among older adults: the health and retirement study, J Aging Health, 2014; 26: 1060-75.

[2] Burns ER, Stevens JA, Lee R. The direct costs of fatal and non-fatal falls among older adults - United States, J Safety Res, 2016; 58: 99-103.

[3] Gillespie LD, Robertson MC, Gillespie WJ. Interventions for preventing falls in older people living in the community, Cochrane Database Syst Rev, 2012; 9: CD007146.

[4] Hausdorff JM, Rios DA, Edelberg HK. Gait variability and fall risk in community-living older adults: A 1 year prospective study, Arch Phys Med Rehabil, 2001; 82: 1050-1056.

[5] Ambrose AF, Paul G, Hausdorff JM. Risk factors for falls among older adults: a review of the literature, Maturitas, 2013; 75: 51-61.

[6] Bergen G, Stevens MR, Burns ER. Falls and Fall Injuries Among Adults Aged $\geqslant 65$ Years - United States, 2014, MMWR Morb Mortal Wkly Rep, 2016; 65: 993-998.

[7] Harber D. Health promotion and aging: Practical applications for health professionals (3rd ed.), New York: Springer Publishing Company, Inc; 2004.

[8] Kim S, Lockhart T. Lower limb control and mobility following exercise training, Journal of Neuroengineering and Rehabilitation, 2012; 9: 15.

[9] Seo J, Kim S. Asymmetrical slip propensity: required coefficient of friction, Journal of Neuroengineering and Rehabilitation, 2013; 10: 84.

[10] Seo J, Kim S. Prevention of potential falls of elderly healthy women: gait asymmetry, Educational Gerontology, 2014; 40(2): 123-137.

[11] Winter D. Human balance and posture control during standing and walking, 1995; 3: 193-214.

[12] Smith A, Ulmer F, Wong D. Gender differences in postural stability among children, Journal of Human Kinetics, 2012; 33: 25-32.

[13] Gray V, Ivanova T, Garland S. Reliability of center of pressure measures within and between sessions in individuals post-stroke and healthy controls, Gait and Posture, 2014; 40: 198-203.

[14] Moghadam M, Ashayeri H, Salavati M, Sarafzadeh J, Taghipoor K, Saeedi A, Salehi R. Reliability of COP of postural stability in health older adults, Gait and Postural, 2011; 33(4): 651-655.

[15] Maurer C, Mergner T, Peterka RJ. Multisensory control of human upright stance, Exp Brain Res, 2006; 171: 231-50.

[16] Piirtola M, Era P. Force platform measurements as predictors of falls among older people - a review, Gerontology, 2006; 52: 1-16.

[17] Pajala S, Era P, Koskenvuo M, Kaprio J, Törmäkangas T, Rantanen T. Force platform balance measures as predictors of indoor and outdoor falls in community-dwelling women aged 63-76 years, J Gerontol: Med Sci, 63A, 2008; 2: 171-178.

[18] Park WH, Kim DK, Yoo JC, Lee YS, Hwang J, Chang MJ, Park YS. Correlation between dynamic postural stability and muscle strength, anterior instability, and knee scale in anterior cruciate ligament deficient knees, Archives of Orthopaedic and Trauma Surgery, 2010; 130(8): 1013-1018. 
[19] Sumway-Cook A, Woollacott M. Motor control therapy and practical applications ( $2^{\text {nd }}$ ed.), LWW, Philadephia; 2001: 228-240.

[20] Swanenburg J, Bruin E, Kathrin F, Uebelhart D, Mulder T. The reliability of postural balance measures in single and dual tasking in elderly fallers and non-fallers, BMC Musculoskeletal Disorder, 2008; 9: 162.

[21] Buatois S, Gueguen G, Gauchard C, Benetos A, Perrin P. Posturography and risk of recurrent falls in health noninstitutionalized persons aged over 65, Gerontology, 2006; 52: 345-352.

[22] Hashimoto F, Ogawa R, Kameyama O. Control engineering and electomyographic kinesiology analyses of normal human gait, Journal of Orthopaedic Science, 2000; 5: 139-49.

[23] Lockhart T, Kim S. Relationship between hamstring activation rate and heel contact velocity: Factors influencing agerelated slip-induced falls, Gait and Posture, 2006; 24: 23-34.

[24] Lockhart T, Woldstad J, Smith J. Effects of age-related gait changes on the biomechanics of slips and falls, Ergonomics, 2006; 46(12): 1136-1160.

[25] Sohn J, Kim S. Falls study: proprioception, postural stability, and slips, Bio-Medical Materials and Engineering, 2015; 26: S693-703.

[26] Judge JO. Training to maintain mobility and prevent disability, Am J Prev Med, 2003; 25: 150-156.

[27] Li F, Harmer P, Fitzgerald K, Eckstrom E, Stock R, Galver J, Maddalozzo G, Batya S. Tai Chi and Postural stability in patients with Parkinson's disease, New England Journal of Medicine, 2012; 366: 511-519.

[28] Gardner A, Katzel L, Sorkin J, Goldberg A. Effects of long-term exercise rehabilitation on claudication distances in patients with peripheral arterial disease: a randomized controlled trial, Journal of Cardiopulm Rehabil, 2002; 22(3): 192-198.

[29] Yang Y, Wang R, Chen Y, Kao M. Dual-task exercise improve walking ability in chronic stroke: a randomzed controlled trial, Arch Phys Med Rehabil, 2007; 88(10): 1236-1240.

[30] Woo J, Hong A, Lau E, Lynn H. A randomized controlled trial of Tai Chi and resistance exercise on bone health, muscle strength and balance in community-living elderly people, Age Ageing, 2007; 36(3): 262-268.

[31] Marini M, Monaci M, Manetti M, Piazza M, Paternostro F, Sgambati E. Dancesport as physical activity be associated with the concept of "successful aging"? Journal of Sports Medicine and Physical Fitness, 2015; 55(10): 1219-1226.

[32] Kim S, Kim M, Ahn Y, Lim H, Kang S, Cho J, Park S, Song S. Effect of Dance exercise on cognitive function in elderly patients with metabolic syndrome: a pilot study, Journal of Sports Science and Medicine, 2011; 10(4): 671-678.

[33] Lukić A. Relations between some motor skills and efficiency of performing the basic elements of technique in sport dance. Unpublised Master's thesis. Univerzitet Banja Luka, Fakultet fizičkog vaspitanja i sporta, 2006.

[34] Wu H, Gau J, Hsu C, Tu J, Tsao T. Effects of Habitual Low-impact Dance on the Balance and Torque of the Knee of Older Female Individuals, Advances in Physical Education, 2012; 2(2): 39-43.

[35] Lee H, Lee M, Hong K. Effects of 9 weeks of Dancesport training on variables related to falling injury in the elderly women, Korean Journal of Sport Science, 2009; 20(4): 778-790.

[36] Kim E, Choi H. The effect of Dancesport Participation on the vascular variables and blood leptin in obese middle-aged women, Journal of the Korean Society of Dance Science, 2014; 30(4): 67-80.

[37] Park SH, Lee K, Lockhart T, Kim S. Effects of sound on postural stability during quite standing, Journal of NeuroEngineering and Rehabilitation, 2011; 8: 67.

[38] Eyigor S, Karapolat H, Durmaz B, Ibisoglu U, Cakir S. A randomized controlled trial of Turkish folklore dance on the physical performance, balance, depression and quality of life in older women, Archives of Gerontology and Geriatrics, 2009; 48(1): 84-88.

[39] Kim J, Yun C, Pack S. Effects of Dancesports program on changes in the thickness of femoral muscles and knee function in CKP middle-aged women, Journal of Dance Education, 2013; 30(1): 209-220.

[40] Lockhart TE, Woldstad JC, Smith JL. Assessment of Slip Severity Among Different Age Groups, ASTM STP 1424, Metrology of Pedestrian Locomotion and Slip Resistance. American Society for Testing and Materials, West Conshohocken, PA; 2002.

[41] Carpenter M, Frank J, Silcher C, Peysar G. The influence of postural threat on the control of upright stance. Exp Brain Res, 2001; 138: 210-218.

[42] Aagaard P, Simonsen E, Andersen J, Magnusson P, Dyhre-Poulsen P. Increased rate of force development and neural drive of human skeletal muscle following resistance training, Journal of Applied Physiology, 2003; 93: 1318-1326.

[43] Mador M, Erkan B, Ajay A, Mary S, Thomas K. Endurance and strength training in patients with COPD, Chest, 2004; 125: 2036-2045.

[44] Lukic A, Bijelic S, Zagorc M, Zuhric-Sebic L. The importance of strength in sport dance performance technique, SportLogia, 2011; 7(1): 61-67.

[45] Uzunović S. Uticaj antropomotoričkih sposobnosti na uspješnost u sportskom plesu (Influence of motor abilities to success in sport dance). Unpublised Master's thesis. Univerzitet Niš, Fakultet fizičke culture; 2004.

[46] Uzunović S. The transformation of strength, speed and coordination under the influence of sport dancing (Transformacija snage, brzine i koordinacije pod uticajem modernog sportskog plesa). Facta Universitas, 2008; 6: 135-146. 
[47] Liu J, Lockhart T. Aging effect on initial postural responses of unperturbed foot to unexpected slips, 50th Annual Meeting of the Human Factors and Ergonomics Society, HFES 2006 - San Francisco, CA, United States, Proceedings of the Human Factors and Ergonomics Society, 2006; 1341-1345.

[48] Angyan L, Teczely T, Angyan Z. Factors affecting postural stability of health young adults, Acta Physiol Hung, 2007; 94(4), 289-299.

[49] Hrysomallis C, Goodman C. A review of resistance exercise and posture realignment, Journal of Strength and Conditioning Research, 2001; 15(3): 385-390.

[50] Bloem BR, Allum JH, Carpenter MG, Honegger F. Is lower leg proprioception essential for triggering human automatic postural responses? Experimental Brain Research, 2002; 130(3): 375-391.

[51] Yaggie JA, McGregor SJ. Effects of isokinetic ankle fatigue on the maintenance of balance and postural limits, Arch Phys Med Rehabil, 2002; 83(2): 224-8.

[52] Williams V, Nagai T, Sell T, Abt J, Rowe R, McGrail M, Lephart S. Prediction of Dynamic Postural Stability During Single-Leg Jump Landings by Ankle and Knee Flexibility and Strength, Journal of Sport Rehabilitation, 2016; 25(3): 266-272.

[53] Iwamoto J, Suzuki H, Tanaka K, Kumakubo T, Hirabayashi H, Miyazaki Y, Sato Y, Takeda T, Matsumoto H. Preventative effect of exercise against falls in the elderly: a randomized controlled trial, Osteoporosis International, 2009; 20(7): 1233-1240.

[54] Emilio E, Fidel H, Pilar J, Pedro L, Antonio M. The association of flexibility, balance, and lumbar strength with balance ability: risk of falls in older adults, Journal of Sports Science and Medicine, 2014; 13: 349-357. 